\title{
Konsep Pendidikan Multikultural Menurut Nadirsyah Hosen
}

\author{
Anah Nurhasanah \\ Institut Agama Islam Darussalam (IAID), Ciamis-Jawa Barat \\ E-mail: anah.kawali17@gmail.com \\ Ahmad Nabil Atoillah \\ Institut Agama Islam Darussalam (IAID), Ciamis-Jawa Barat \\ Ahmad Abdur Rohman \\ Institut Agama Islam Darussalam (IAID), Ciamis-Jawa Barat
}

\begin{abstract}
Education is the most important factor in efforts to develop potential and knowledge and cultural values. In the context of a society that has diversity in various aspects ranging from religion, ethnicity, ethnicity to culture, it needs deep understanding as well as awareness of the importance of multicultural education to maintain togetherness and integrity of a nation. In an effort to realize these efforts, multicullural education is interpreted as a process of understanding the diversity that exists and the similarities to be able to respect each other. In order to realize an understanding of multiculturalism, it must be endeavored in the right way, namely through education. The focus of this research is (1) what is the concept of multicultural education according to Nadirsyah Hosen? (2) how is the relevance of Nadirsyah Hosen's multicultural education concept with the aim of Islamic education? In order to find answers to the above questions, the authors conducted research using a library research research approach or commonly referred to as literature review research. Sources of data obtained for this research library research can be in the form of research journals, dissertations, theses, theses, research reports, text books, papers, seminar reports, and / or official publications of the government or other institutions. The references are then processed using the content analysis method which aims to obtain the contents of the data and information then analyzed with a deductive thinking model, which departs from general theory to find applicative conclusions. The findings in this study are as follows: (l) The concept of multicultural education in Nadirsyah Hosen's view is to implement education that engages students who are not only intellectually intelligent but aware of national diversity. Providing equal opportunities to all students in obtaining education regardless of differences in racial, cultural, ethnic and religious backgrounds, in order to avoid discriminatory attitudes, fanaticism so as to form a tolerant attitude, respect for differences and culture. (2) Nadirsyah Hosen's
\end{abstract}


thoughts regarding multicultural education are relevant to the goals of Islamic education. In Islam it is explained that the purpose of education is in accordance with the purpose of the creation of Allah's creatures. Becoming the unifier of the nation forms human beings who not only worship Allah or Ghair Mahdah but also respect the diversity of the nation which is known as mahdah worship. The relation with multicultural education is that religion has strong foundations in implementing education that understands a pluralistic nation.

Keywords: The Concept of Multicultural Education, Nadirsyah Hosen, The Purpose of Islamic Education

\section{PENDAHULUAN}

Manusia adalah makhluk yang diciptakan berbeda-beda dan beragam. dari jenis kelamin, suku bangsa, bahasa, hingga agama. Sejatinya keragaman ini menjadi alat perekat harmonisasi bangunan kebersamaan antar sesama. Namun faktanya. perbedaan SARA acapkali memicu timbulnya sebuah konflik dan ketegangan. Bukankah kemajemukan merupakan sunatullah yang meski terjadi, sebagaimana adanya langit dan bumi. Pengingkaran atas kemajemukan berarti juga pembangkangan atas kehendak-Nya (Aqil, 1999:203).

Kemajemukan (pluralitas), keanekaragaman (diversitas), serta kebermacam-macaman (multiformisme) masyarakat dan kebudayaan di Indonesia merupakan kenyataan sekaligus keniscayaan, sejak dulu sebelum terbentuk negara-bangsa. Ini harus kita akui secara jujur, terima dengan lapang dada, resapi dengan penuh kesadaran, kelola rawat dengan cermat, dan jaga dengan penuh suka cita, bukan harus kita tolak, pungkiri, abaikan, sesalkan, biarkan dan ingkari hanya karena kemajemukan dan keanekaragaman ternyata telah menimbulkan ekses negatif dan resiko kritis belakangan ini, antara lain benturan masyarakat dan kebudayaan lokal di berbagai tempat di Indonesia(Rasiyo, 2005:47).

Pendidikan menjadi salah satu kunci penting sebagai instrumen membangun peradaban manusia dan bangsa. Keberadaannya masih diyakini mempunyai peran besar dalam membentuk karakter individuindividu yang dididiknya. Hal tersebut dengan suatu pertimbangan bahwa salah satu fungsi pendidikan adalah untuk meningkatkan keberagamaan peserta didik dengan keyakinan budaya dalam agama sendiri dan memberikan kemungkinan keterbukaan untuk mempelajari dan mempermasalahkan budaya Iain sebatas untuk menumbuhkan sikap toleransi(Maarif, 2020:22). Secara sederhana pendidikan multikultural, dapat didefenisikan sebagai pendidikan keberagaman dalam merespon perubahan demografis dan kultural lingkungan masyarakat tertentu atau bahkan dunia secara keseluruhan dalam cakupan budaya agama. 


\section{BESTARI}

Vol. 17, No. 2, 2020

p-ISSN 1907-1337; e-ISSN 2807-6532

Dalam hal ini, dunia pendidikan diyakini mampu menyadarkan dan menbawa pesan-pesan universal agar mengurangi konflik- konflik antar kultur. untuk menghindari munculnya aksi intoleransi, kekerasan, konflik-konflik bernuansa SARA, baik itu dalam dunia pendidikan ataupun dunia politik di masyarakat. Jadi, pendidikan multikultural adalah suatu keniscayaan atau merupakan paradigma dan metode untuk menggali potensi keragaman etnik dan kultural Nusantara, dan mewadainya dalam suatu manajemen konflik yang mewadai"(Baidhawy, 2005:17).

pendidikan multikultural adalah konsep sekaligus praktis pendidikan yang mencoba untuk memberikan pemahaman mengenai keanekaragaman ras, etnis, dan budaya dalam suatu masyarakat. Dalam praktiknya pendidikan ini berupaya membangun interaksi sosial yang demokratis, toleran, dan saling menghormati antara orang-orang yang berasal dari latar belakang yang berbeda-beda (Gaus dkk, 2010:4).

Nadirsyah Hosen menggagas mengenai konsep pendidikan multikultural yaitu proses mengembangkan seluruh potensi peserta didik yang posisinya adalah seorang hamba sekaligus sebagai khalifah fil ard dengan adanya proses kemerdekaan diri yang memunculkan sikap kemanuisaan dengan cara menghargai pluralitas dan heterogenitasnya kemerdekaan orang lain. Sebagai konsekuensinya jalan demokrasi dan kepemimpinan yang di gagas oleh Nadirsyah Hosen akan memunculkan persatuan bangsa dalam masyarakat yang plural.

Uraian diatas dapat disimpulkan bahwa pendidikan berperan penting dalam membangun karakter siswa yang heterogen supaya tumbuh rasa keterbukaan dan sikap toleransi terhadap keberagaman budaya. Hal ini sesuai dengan konsep pendidikan multikultural menurut Nadirsyah Hosen.

\section{KAJIAN TEORI}

Secara etimologis berasal dari kata dasar didik yang diberi awalan pen- dan akhiran -an. Dalam kamus tersebut, pendidikan berarti proses pengubahan sikap dan tingkah laku seseorang atau kelompok orang dalam usaha mendewasakan manusia melalui upaya pengajaran dan pelatihan(Nata, 1997:4). Adapun pengertian pendidikan secara terminologi dapat dilihat dalam pengertian secara khusus dan secara luas, dalam arti khusus menurut Sadulloh pendidikan hanya dibatasi sebagai usaha orang dewasa dalam membimbing anak yang belum dewasa untuk mencapai kedewasaannya. Setelah anak menjadi dewasa dengan segala cirinya maka pendidikan dianggap selesai. Pendidikan dalam arti khusus ini menggambarkan upaya pendidikan yang terpusat dalam lingkungan keluarga(Sadulloh, 2007:54).

a. Tujuan Pendidikan 
Tujuan pokok pendidikan adalah mendidik budi pekerti dan membentuk jiwa. Apapun mata pelajarannya haruslah mengandung pelajaran-pelajaran akhlak,termasuk akhlak toleransi. Setiap pendidik haruslah memikirkan akhlak ini melihat keadaan Negara Indonesia memiliki berbagai keragaman. Sehingga pendidikan multikultural perlu di dalami dan dipahami.

Konsep Pendidikan Multikultural

Istilah pendidikan multikutural merupakan gabungan dari dua kata yaitu pendidikan dan multikultural. Kedua kata tersebut akan diuraikan satu persatu sebelum didefinisikan secara keseluruhan yaitu pendidikan multikultural. Hal ini bertujuan supaya konsep pendidikan multikultural dapat dipahami secara mendasar.

Makna pendidikan merupakan terjemahan dari kata education, yang kata dasarnya adalah educate atau bahasa latinnya educo. Educo berarti mengembankan dari dalam; mendidik; dan melaksanakan hukum kegunaan. Ada juga yang mengatakan bahwa kata education berasal dari kata latin educare yang memiliki arti konotasi melatih atau menjinakan (seperti dalam konteks manusia melatih hewan-hewan yang liarmenjadi semakin jinak, sehingga bisa diternakkan), dan menyuburkan (membuat tanah lebih menghasilkan banyak buah berlimpah karena tanahnya telah digarap dan diolah) (Fadillah, 2017: 45).

Menurut konsep diatas pendidikan merupakan sebuah proses yang membantu menumbuhkan, mengembangkan, mendewasakan, membuat yang tidak tertata atau liar menjadi semakin tertata, semacam proses penciptaan sebuat kultur dan tatakeraturan dalam diri sendiri maupun diri orang lain. Dengan kata lain, pendidikan tidak hanya dimaknai sebagai transfer pengetahuan, tetapi sebagai proses pengembangan berbagai macam potensi yang ada dalam diri manusia, seperti kemampuan akademis, relasional, bakat-bakat, talenta, kemampuan fisik dan daya-daya seni.

\section{METODOLOGI}

Jenis penelitian yang digunakan dalam penelitian ini adalah penelitian kualitatif. Sementara itu, metode yang digunakan adalah metode penelitian kepustakaan. Dalam penelitian studi pustaka, menurut Supriyadi (2016: 85), setidaknya ada empat ciri utama penulis perlu perhatikan diantaranya:

1. Bahwa penulis atau peneliti berhadapan langsung dengan teks (nash) atau data angka.

2. Data pustaka bersifat siap dipakai artinya peneliti tidak terjun langsung kepalangan karena peneliti berhadapan langsung dengan sumber data yang ada di perpustakaan.

3. Bahwa data pustaka umumnya adalah sumber sekunder, dalam arti bahwa peneliti memperoleh bahan atau data dari tangan kedua dan bukan data orisinil dari data pertama di lapangan.

4. Bahwa kondisi data pustaka tidak dibatasi oleh ruang dan waktu. 


\section{BESTARI}

Vol. 17, No. 2, 2020

p-ISSN 1907-1337; e-ISSN 2807-6532

Dalam penelitian ini penulis menggunakan dua jenis data yang dipergunakan sebagai sumber penelitian yaitu sumber data primer dan sumber data sekunder. (1) Sumber data primer, yaitu Karya- karya Nadirsyah Husein, yaitu: Tafsir Alquran Di Medsos, Saring Sebelum Sharing, Islam Yes Khilafah No, Ngaji Fikih, dan Kiai Ujang di Negeri Kangguru. (2) Sumber data sekunder, yaitu data yang mamuat informasi pendukung dalam penelitian ini untuk mendapatkan informasi tentang pendidikan multikultural apa saja yang terdapat dalam data primer tersebut. Data tersebut dapat berwujud buku, teks dan artikel sejarah, otobiografi, biografi, jurnal sastra, atau yang lainnya. (3) Teknik Pengumpulan Data

Teknik pengumpulan data merupakan langkah yang paling utama dalam penelitian, karena tujuan dari penelitian adalah mendapatkan data. Tanpa mengetahui teknik pegumpulan data, maka penetitian tidak akan mendapatkan data yang memenuhi standar data yang ditetapkan (Sugiyono, 2018: 308).

Pada bagian ini peneliti harus menjelaskan dengan cara apa data diperoleh dan instrumen apa yang digunakan untuk memperoleh data tersebut. Mirzaqon dan Purwoko (dalam Sari, 2020:45) mengemukakan teknik pengumpulan data dalam penelitian kepustakaan bisa dengan dokumentasi, yaitu mencari data berupa catatan, buku, makalah, artikel, jurnal dan sebagainya. Instrumen penelitian data yang digunakan bisa berupa daftar check-list klasifikasi bahan penelitian, skema/peta penulisan dan format catatan penelitian.

Keabsahan data dilakukan untuk membuktikan apakah penelitian yang dilakukan benar-benar merupakan penelitian ilmiah sekaligus untuk menguji data yang diperoleh. Uji keabsahan data dalam penelitian kualitatif meliputi uji, credibility, transferability, dependability, dan confirmability (Sugiyono, 2018: 366).

Keabsahan data teks, menggunakan standar dengan mempercayakan teks yang diambil dari penerbit yang memiliki kreadibilitas dan kepercayaan dari masyarakat yaitu karya Nadirsyah Hosen.

Analisis data bertujuan untuk mengorganisir, menyediakan struktur, dan memperoleh arti dari data penelitian. Mirzaqon dan Purwoko mengemukakan teknik analisis data yang digunakan dalam penelitian kepustakaan bisa dengan menggunakan metode analisis isi (Content Analysis). Fraenkel dan Wallen menyatakan analisis isi adalah sebuah alat penelitian yang difokuskan pada konten aktual dan fitur internal media. Teknik ini dapat digunakan peneliti untuk mengkaji perilaku manusia secara tidak langsung melalui analisis terkadap komunikasi mereka seperti: buku, teks, esay, koran, novel, artikel, majalah, lagu, gambar iklan, dan semua jenis komunikasi yang dapat dianalisis (Sari, 2020: 47). 
Langkah-langkah peneliti dalam menganalisis data menurut Milles dan Huberman dalam (Sari, 2020:48) , sebagai berikut: (1) Reduksi data (data reducation), pada tahap awal ini melakukan pemilihan, pemfokuskan, penyerderhanaan, abstaksi, dan pentrasformasian data mentah dalam catatan-catatan tertulis. (2) Penyajian data (data display), tahap ini data yang sudah direduksi kemudian didisplay hingga memberikan pemahaman terhadap data tersebut agar bisa menentukan langkah selanjutnya. (3) Gambaran kesimpulan (conclusion drawing), setelah reduksi dan display data terlaksana, maka dilakukan penarikan kesimpulan dari data yang diteliti. Dari kesimpulan tersebut dipaparkan penemuan baru dari penelitian yang dilakukan.

Berdasarkan uraian analisis data yang digunakan dalam penelitian ini terdiri dari tiga langkah, yaitu reduksi data, penyajian data dan gambaran kesimpulan data.

\section{HASIL PENELITIAN DAN PEMBAHASAN}

\section{Biografi Nadirsyah Hosen}

Ibrahim Hosen, L.M.L (1917 - 2001) adalah ulama Fiqih Indonesia kenamaan. Ia putra dari pasangan K.H. Hosen dan Siti Zawiyah. Ayahnya seorang ulama, saudagar berdarah Bugis dan pendiri Mu'awanatul Khair Arabische School di Tanjung Karang, Lampung. Ibunya keturunan ningrat kerajaan selebar Bengkulu. Kyai kelahiran Bengkulu 1 Januari 1917 ini menempuh pendidikan pertamanya di Madrasah Ibtidaiyah Al saggaf Singapura, lalu melanjutkan studi di Solo, Banten, Sukabumi, dan lama nyantri dengan K. H Abbas di buntet Pesantren, Cirebon (Hosen, 2020:443).

Nadirsyah Hosen, Ph.D. Menempuh pendidikan formal dalam dua bidang yang berbeda, Ilmu Syari'ah dan Ilmu Hukum, sejak S-1, S-2, dan S-3. Pemegang dua gelar Ph.D. ini memilih berkiprah di Australia, hingga meraih posisi Associate Professor di Fakultas Hukum, University of Wollongong. Namun kemudian, dia "diajak untuk pindah ke Monash University pada 2015, Monash Law School adalah salah satu Fakultas Hukum terbaik di dunia. Baru setahun pindah ke Monash, beliau sudah diminta mengurusi Monash Malaysia Law Program, sebuah program unggulan melibatkan mahasiswa dari Australia, Kanada, Belanda, Jerman, dan Prancis. Di Kampus Monash, beliau mengajar Hukum Tata Negara Australia, Pengantar Hukum Islam, dan Hukum Asia Tenggara(Hosen,2018:352).

Pergaulannya luas, akrab dengan para profesor kelas dunia, begitu juga dengan para gus dan kiai pondok pesantren di Tanah Air. Ini karena pembawaan Gus Nadir sendiri yang ramah, humoris, santun, dan santai. Dia pun selalu mengenang pesan ibunya, “Tetap sederhana, Nak!”, itulah sosok Nadirsyah Hosen (Hosen, 2019:326). Pada tahun 2019 Gus Nadir 


\section{BESTARI}

Vol. 17, No. 2, 2020

p-ISSN 1907-1337; e-ISSN 2807-6532

akan memulai membuka kursus online keislaman untuk menebar Islam yang rahmatan lil alamin di ranah medsos (Hosen, 2019:276).

\section{Konsep Pendidikan Multikultural Menurut Nadirsyah Hosen}

Nadirsyah Hosen tidak menjelaskan langsung mengenai konsep pendidikan multikultural di dalam karyanya, namun ada makna tersirat yang disampaikan mengenai konsep pendidikan multikultural dari beberapa cerita dan perdebatan perbedaan madzhab. Menurut beliau tiap-tiap Negara itu terjadi dari beberapa golongan yang masing-masing mempunyai sifat dan kepercayaan sendiri-sendiri. Adapun keunikan itu wajar adanya. Menurutnya, persatuan dan kesatuan kebangsaan jangan dicapai dengan mempersatukan segala keadaan yang bermacam-macam, sifat, dan bentuknya. Persatuan haruslah dengan kodrat alam, yakni persatuan dan kesatuan yang terjadi karena adanya kesamaaan keperluan yang penting, bukan karena paksaan mempersatukan hal-hal yang tidak mungkin dipersatukan (Hosen, 2020:89).

Menurut Nadirsyah Hosen, pendidikan harus menerapkan nilainilai multikultural, karena perbedaan tidak bisa dihindari meskipun dalam satu agama yaitu berbeda pemahaman ibadah, maka sikap toleransi atas keberagaman tersebut harus dikedepankan. Pendapat yang benar, namun mengandung kemungkinan salah. Pendapat selain itu salah, namun tidak menutup kemungkinan mengandung kebenaran (Hosen, 2015:35). Nadirsyah Hosen mempunyai konsep pemikiran yang relevan dengan pendidikan multikultural di antara lain; 1) kemerdekaan Diri, Tertib Damai, dan 2) Humanisme (kemanusiaan).

a. Kemerdekaan Diri, Tertib Damai

Gagasan pendidikan multikultural Nadirsyah Hosen dalam konsep kemerdekaan diri, tertib damai adalah suatu pendidikan seseorang dengan mengedepankan pengisian jiwa kemandirian yang berlandaskan pendidikan tanpa adanya paksaan sesuai kodrat yang harus ditumbuh kembangkan sehingga akan memperoleh manusia yang mandiri, bertaqwa kepada Tuhan, cerdas, berketerampilan dan bertanggung jawab terhadap apa yang dia ambil.

Kemanusiaan (humanisme)

Gagasan pendidikan multikultural konsep humanisme adalah pendidikan yang berprinsif manusia sebagai makhluk Tuhan yang berbeda dengan makhluk lainnya yang memiliki pandangan hidup yang berbeda-beda sesuai dengan bakat, pemikiran dan hasil belajarnya. Pandangan lain juga ialah pendidikan multikultural humanisme ini upaya untuk memajukan, menumbukan budi pekerti, dan pikiran sehingga terbentuklah kesempurnaan hidup yang selaras dan serasi dengan dunianya.

Demokrasi dan kepemimpinan

Konsep yang dibangun Nadirsyah Hosen tentang demokrasi dan kepemimpinan adaah faham yang mengarahkan kepada kebebasan 
terhadap hak individu dan bermuara terhadap kemerdekaan, kemandirian dalam menumbuh kembangkan jiwa kemandirian serta berasaskan kesejahteraan social, keselamatan bersama dalam satu leadership sehingga memperoleh cinta kasih sesuai hati nurani dan kebahagiaan bersama.

Relevansi Pemikiran Multikultural Nadirsyah Hosen Dengan Tujuan Pendidikan Islam

Pemikiran Nadirsyah Hosen mengenai konsep pendidikan multikultural dengan tujuan pendidikan Islam memiliki relevansi. Konsep pendidikan multikultural yang memiliki karakter memberikan kesempatan yang sama bagi seluruh peserta didik tanpa melihat perbedaan latar belakang ras, suku, etnis, budaya beagama dan agama. Hal ini sama dengan yang menjadi tujuan pendidikan Islam. Mulai dari tujuan tertinggi yaitu sesuai dengan diciptakannya manusia kemudian tujuan pendidikan umum yang mana taraf pencapaiannya dapat diukur dengan perubahan tingkah laku, kepribadian dan akhlak seseorang yang mengacu pada tujuan tertinggi yaitu Insan Kamil. Pada tujuan pendidikan khusus menjelaskan bahwa tujuan pendidikan yang bersifat relatif artinya menyesuaikan keadaan yang berubah-ubah sesuai dengan keadaan sosial yang ada. Dengan demikian titik relevansi dari konsep pendidikan multikultural dengan tujuan pendidikan Islam adalah bagaimana keduanya melibatkan budaya dan keadaan sosial masyarakat (Ramayulus,2002:218).

\section{SIMPULAN}

Berdasarkan hasil penelitian dan pembahasan yang telah dilakukan pada bab sebelumnya, peneliti dapat mengambil kesimpulan sebagai berikut: (1) Konsep pemikiran Nadirsyah Hosen mengenai pendidikan multikultural terdapat tiga gagasan, yaitu konsep kemerdekaan diri, tertib damai (zelfbeschik kingsrecht); kemanusiaan (humanisme); dan demokrasi dan kepemimpinan. (2) Dalam Islam dljelaskan bahwa tujuan pendidikan sesuai dengan tujuan diciptakannya makhluk Allah. Menjadi pemersatu bangsa membentuk insan kamil yang tidak hanya beribadah kepada Allah atau ghair mahdah namun juga menghargai keberagaman bangsa yang disebut sebagai ibadah mahdah. Relevansinya dengan pendidikan multikultural bahwa agama memiliki dasar-dasar yang kuat dalam menerapkan pendidikan yang memahami bangsa yang plural. 


\section{DAFTAR PUSTAKA}

Aqil, Said Siradj. 1999. "Islam Kebangsaan: Fikih Demokratikkaum Santri”. Jakarta: pustaka Ciganjur.

Aqil, Said Siradj. 1999. "Islam Kebangsaan: Fikih Demokratikkaum Santri”. Jakarta: pustaka Ciganjur.

Baidhawy, Zakiyuddin. 2005. "Pendidikan Agama Berwawasan Multikultural". Jakarta: Erlangga.

Gaus, Ahmad, Dkk. 2010. "Cerita Sukses Pendidikan Multikultural Di Indonesia” Jakarta: Yayasan TIFA.

Hosen, Nadirsyah. 2019. "Kiai Ujang Di Negeri Kangguru". Bandung: Mizan Media Utama.

Hosen, Nadirsyah. 2019. "Saring Sebelum Sharing". Yogyakarta: PT Bentang Pustaka.

Hosen, Nadirsyah. 2018. "Islam Yes Khilafah No". Yogyakarta: Suka Press.

Hosen, Nadirsyah. 2020. "Ngaji Fikih". Yogyakarta: PT Bentang Pustaka.

Hosen, Nadirsyah. 2017. "Tafsir Al Quran Di Medsos". Yogyakarta: PT Bentang Pustaka.

Maarif, Syamsul.. "Islam dan Pendidikan Pluralisme; Menampilkan Wajah Islam Toleran Melalui Kurikulum PAI Berbasis Kemajemukan”. Disampaikan Dalam Annual Confrence di Lembang Bandung, sumber www. Google.com/pluralism-pendidikan, akses tanggal 7 Juli 2020.

M. Fadillah. "Journal Pembangunan Pendidikan:Pondasi Dan Aplikasi "volume 5, no 1, june 2017.

Nata, Abuddin. 1997. "Filsafat Pendidikan Islam". Ciputat:Logos Wacana Ilmu.

Rasiyo. 2005. "Berjuang Membangun Pendidikan Bangsa : Pijar-pijar Pemikiran dan Tindakan" Malang: Pustaka Kayu Tangan.

Sadulloh, Uyoh. 2007. "Pengantar Filsafat Pendidikan". Bandung: Alfabeta.

Sugiyono. 2018. "Metode Penelitian Pendidikan". Bandung: Alfabeta.

Supriyadi. 2016. "Community Of Practitioners: Solusi Alternatif Berbagai Pengetahuan Antar Pustakawan”. Lentera Pustaka 
